\title{
Airborne measurements of nucleation mode particles II: boreal forest nucleation events
}

\author{
C. D. O'Dowd ${ }^{1}$, Y. J. Yoon ${ }^{1,2}$, W. Junkermann ${ }^{3}$, P. Aalto ${ }^{4}$, M. Kulmala ${ }^{4}$, H. Lihavainen ${ }^{5}$, and Y. Viisanen ${ }^{5}$ \\ ${ }^{1}$ School of Physics \& Centre for Climate and Air Pollution Studies, Environmental Change Institute, National University of \\ Ireland, Galway, University Road, Galway, Ireland \\ ${ }^{2}$ Korea Polar Research Institute, KORDI, 7-50, Songdo-dong, Incheon 406-840, Korea \\ ${ }^{3}$ Fraunhofer Institute for Atmospheric Environmental Research, Kreuzeckbahnstr. 19, \\ 82467 Garmisch-Partenkirchen, Germany \\ ${ }^{4}$ Department of Physical Sciences, P.O. Box 64 (Gustaf Hällströmin katu 2) PL 64, 00014 University of Helsinki, Finland \\ ${ }^{5}$ Finnish Meteorological Institute, Erik Palménin aukio, P.O. Box 503 00101, Helsinki
}

Received: 18 September 2007 - Published in Atmos. Chem. Phys. Discuss.: 13 February 2008

Revised: 17 December 2008 - Accepted: 22 December 2008 - Published: 6 February 2009

\begin{abstract}
Airborne measurements of nucleation mode aerosol concentrations during nucleation events over the boreal forest of southern Finland are reported. Three case studies are analyzed in an attempt to characterise the spatial scales over which these events occur and to identify the source region for particle production. For the cases presented, there is no evidence of nucleation mode particles in the Free Troposphere. Nucleation mode particles are first detected in the surface layer as the nocturnal inversion breaks up and develops into the current-day's new boundary layer. In terms of spatial variability, significant variability in the concentration of nucleation mode particles was observed and was attributed to changes in the topography which comprised a mix of forest canopy and frozen lakes. Measurements over the Gulf of Bothnia indicated no nucleation mode over the sea and confirm that the scale of the events is associated with the boreal forest scale and that the new particles are produced directly above the forest canopy.
\end{abstract}

\section{Introduction}

The atmospheric aerosol system constitutes perhaps one of the most complex atmospheric systems to elucidate due to the many different formation and growth processes, sources and sinks, interactions with gas-phase chemical cycling of

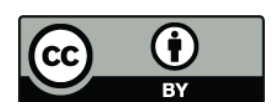

Correspondence to: C. D. O'Dowd (colin.odowd@nuigalway.ie) constituents, and interactions with clouds and the hydrological cycle. Furthermore, aerosols contribute to the direct and indirect radiative forcing of the earth's radiative budget and consequently influence climate (IPCC 2007).

While much attention has been focused on the impact of anthropogenic aerosol emissions on climate and air quality (Hansson and O'Dowd, 2006), the natural aerosol system is of equal importance for two reasons. First, the impact of anthropogenic aerosols can only be quantified once the background natural system has first been quantified and secondly, the natural aerosol system is likely to be involved in feedback processes (Charlson et al., 1987) since their production rates are typically linked to biological activities or ecosystems such as plankton (O'Dowd et al., 2002, 2004) over the ocean and vegetation or forested regions over land where the boreal forest is a significant source of new particles formed through gas to particle conversion processes (Kulmala et al., 2004; O'Dowd et al., 2002; Tunved et al., 2006).

The boreal forest region in Southern Finland has provided an ideal natural laboratory to study the processes driving terrestrial new particle formation processes driven by organic vapour emissions. Large international projects such as BIOFOR (Kulmala et al., 2001) and QUEST (Laaksonen et al., 2003) have brought multi-disciplinary resources together to elucidate the dominant processes.

While the current consensus (Kulmala et al., 2004) on the formation mechanism is that nucleation is most likely driven by sulphuric acid, rather than organic vapours, it is thought that the organic vapours are required to grow the nucleated clusters into quasi-stable aerosol particles larger than $3 \mathrm{~nm}$

Published by Copernicus Publications on behalf of the European Geosciences Union. 

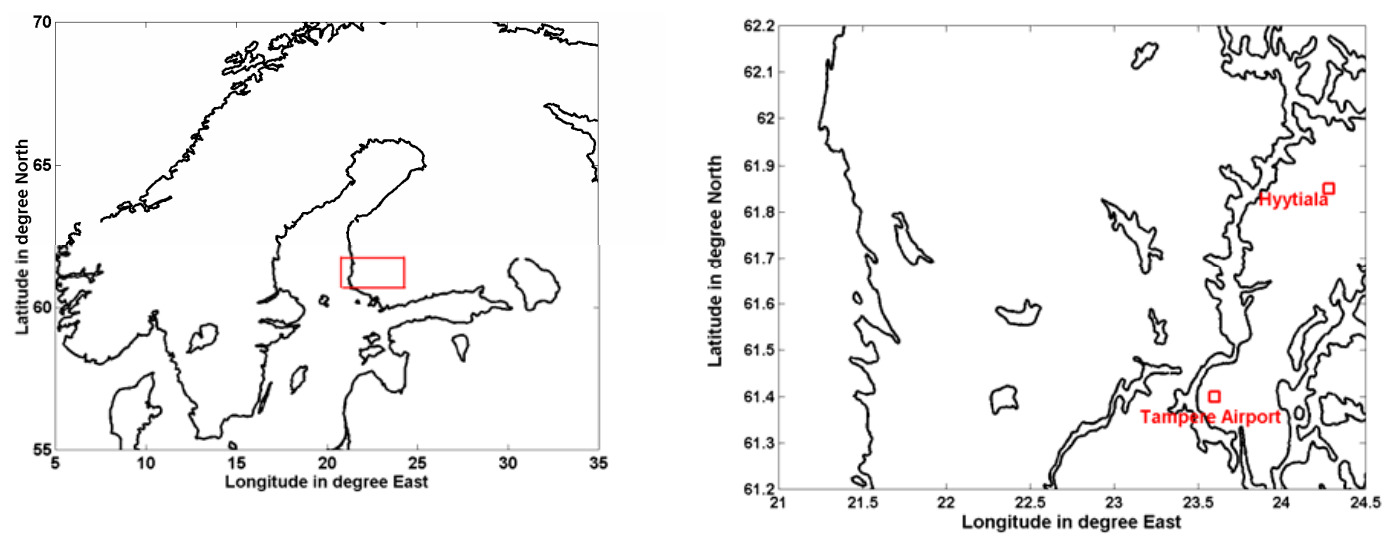

Fig. 1. Map of Finland with zoom box over the aircraft operations area.

(O'Dowd et al., 2002), and even further to sizes larger than $100 \mathrm{~nm}$ where they can contribute to direct and indirect radiative effects. The mechanism of production has been significantly elucidated; however, the location of particle formation and the role of meteorology still remains an open question. For example, Raes (1995) has suggested that nucleation and initial growth takes place in the free troposphere and when these new particles are entrained into the boundary layer, they can grow rapidly into larger sizes. One study over forested regions in Germany also reported particle formation above the surface layer followed by downward mixing into the surface layer (Stratmann et al., 2003). However, mixing diagram analysis of production events over the boreal forest supported more the concept that the particle production occurred in the boundary layer (Nilsson et al., 2001).

This study reports on a specific component of the QUEST project aimed at elucidating the source region of new particle production over the boreal forest utilising aerosol measurements onboard two light aircraft deployed over the forest canopy.

\section{Experimental}

The second QUEST intensive field study took place in March-April 2002 at the Hyytiälä research station. In support of the ground based measurements, two research aircraft were deployed to characterise the nucleation events in terms of source regions and spatial scales.

The GTK Twin Otter Geophysics Research Aircraft (O'Dowd et al., 2007) and the Microlight (Junkermann, 2005) were used for this airborne study. Meteorological sensors for air temperature, pressure and dew point and radiation were fitted as well as a suite of aerosol sensors. For nucleation mode aerosol measurements, a suite of TSI condensation particle counters (CPCs) were deployed to measure particle concentration at sizes lager than $3 \mathrm{~nm}, 6 \mathrm{~nm}$ and $10 \mathrm{~nm}$. Particles larger than $3 \mathrm{~nm}$ were measured using the TSI
3025 ultrafine particle counter while concentrations larger than $6 \mathrm{~nm}$ were measured with a modified TSI $3010(\mathrm{~m})$ and particles larger than $10 \mathrm{~nm}$ were sampled using a standard TSI 3010 CPC. This configuration of CPCs allows crude size distributions between 3-6 and 6-10 $\mathrm{nm}$ to be derived at $1 \mathrm{~Hz}$. The TSI 3025 was connected to the central aerosol flow with a dilution ration of 7 to avoid saturation of counts during the more intense nucleation events. For more detailed sizeresolved measurements, a nano-SMPS scanning over $30 \mathrm{~s}$ was used. Finally, a PHA-CPC was used to examine nucleation mode aerosol growth in butanol vapour to discriminate between organic and inorganic nucleation mode particle compositions. For a detailed summary and discussion on particle sampling and losses, see O'Dowd et al. (2007). In summary, particle losses were minimal down to sizes of $20 \mathrm{~nm}$, increasing to $30 \%$ at $10 \mathrm{~nm}$ and to $65 \%$ at $3 \mathrm{~nm}$. No correction is made in this study. Typical air speed was $55 \mathrm{~ms}^{-1}$.

The microlight aircraft of IMK-IFU, a motorized handglider (Junkermann, 2005), was equipped with sensors for meteorological parameters, temperature and dew point, different radiation measurements, both up- and down welling, and a set of instruments for different sizes of aerosols. Large particles were detected with a Grimm 1.108 aerosol spectrometer and a FSSP, forward scattering spectrometer probe. For the measurement of small size aerosols, two condensation particle counters (CPC's), a TSI 3010 with $10 \mathrm{~nm}$ cut-off size and a TSI 3025 with $3 \mathrm{~nm}$ cut-off, were used similar to the installation on the Twin Otter.

The Hyytiälä SMEAR II research station in Southern Finland was the central location for the ground-based measurement component of QUEST and is shown in Fig. 1. Also, the operating region for the flights is outlined by the red box in the figure. The aircraft was located at Tampere airport and the flight operation area was typically upwind and to the north of Tampere and to the west of the Hyytiälä SMEAR II research station. The terrain is densely populated with forest (typically pine and spruce) and the region is also populated with many lakes and one large river seen orientated 


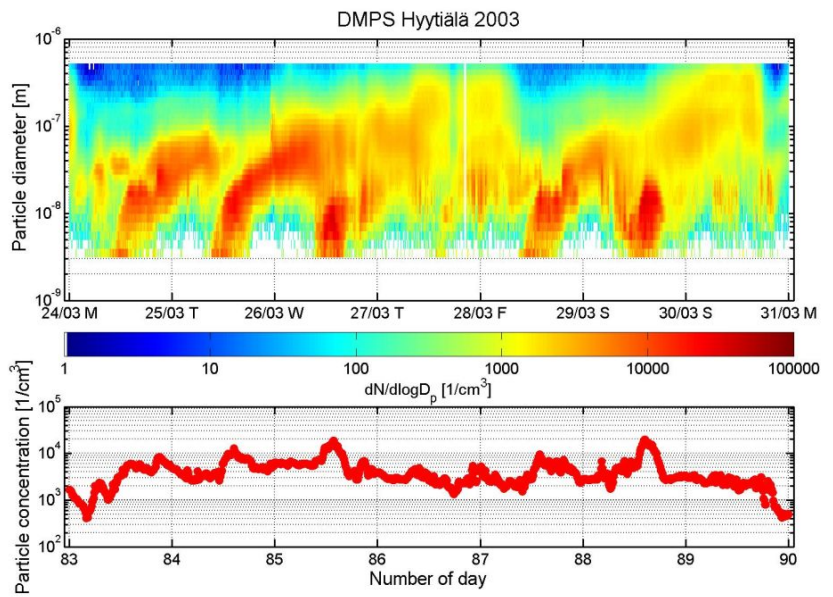

Fig. 2. Size distribution evolution during golden day nucleation events from 24th to 30th March 2003.

north-south and to the west of Hyytiälä. An overview of the QUEST project can be found in Laaksonen et al. (2003).

\section{Results}

During the period 24th to 30th March 2003, 5 strong nucleation events were observed at Hyytiälä. These are illustrated in Fig. 2 where the size and concentration evolution is displayed for particles between $3 \mathrm{~nm}$ and $500 \mathrm{~nm}$ as measured by the dual DMPS system. These events comprised the QUEST II "golden day events". In the context of airborne measurements, flights were undertaken on 3 of these events and are reported on here.

\subsection{Synoptic scale meteorological conditions}

For the three selected days, the synoptic weather conditions are illustrated in Fig. 3. For the first event presented on 25th March 2003, the area was subject to slack weather conditions with a gentle northerly air flow of the order of $1-4 \mathrm{~m} \mathrm{~s}^{-1}$ between the surface and $70 \mathrm{~m}$. On the 26th, the area was subjected to more westerly airflow in between a warm front to the east and a cold from to the north and west. Wind speeds on this day were between $1.5 \mathrm{~ms}^{-1}$ at the surface, increasing to $8 \mathrm{~ms}^{-1}$ at $70 \mathrm{~m}$. The cold front passed through on the 27 th and had moved over Russia by the 28th leaving the whole of Finland exposed to a polar air mass with north-westerly airflow and maximum wind speeds of $8 \mathrm{~ms}^{-1}$ at $70 \mathrm{~m}$. Typically, these conditions lead to slightly unstable air and clear sky. The clear sky leads to strong nocturnal cooling and the development of a stable nocturnal boundary layer which breaks up mid-morning due to increased surface heat flux (Nilsson et al., 2001). (a)

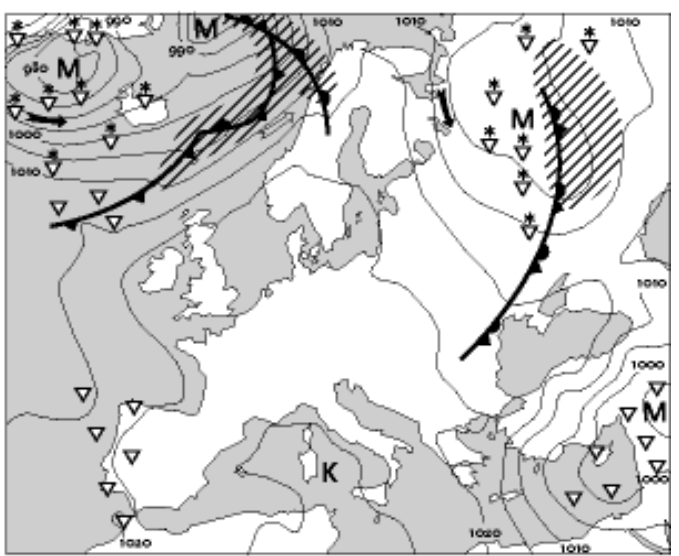

(b)

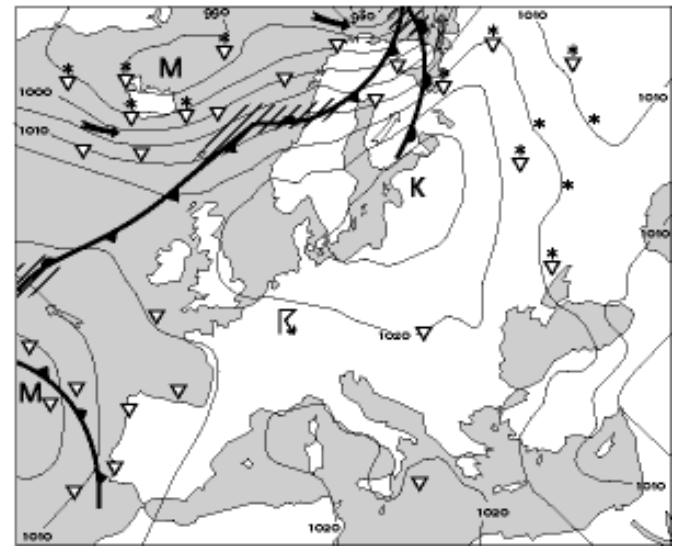

(c)

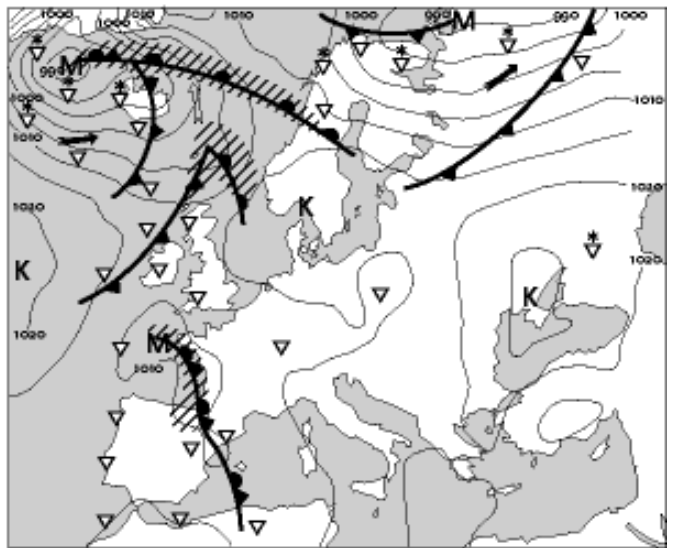

Fig. 3. Synoptic conditions on (a) 25th March 2003, (b) 26th March 2003 and (c) 28th March 2003. 


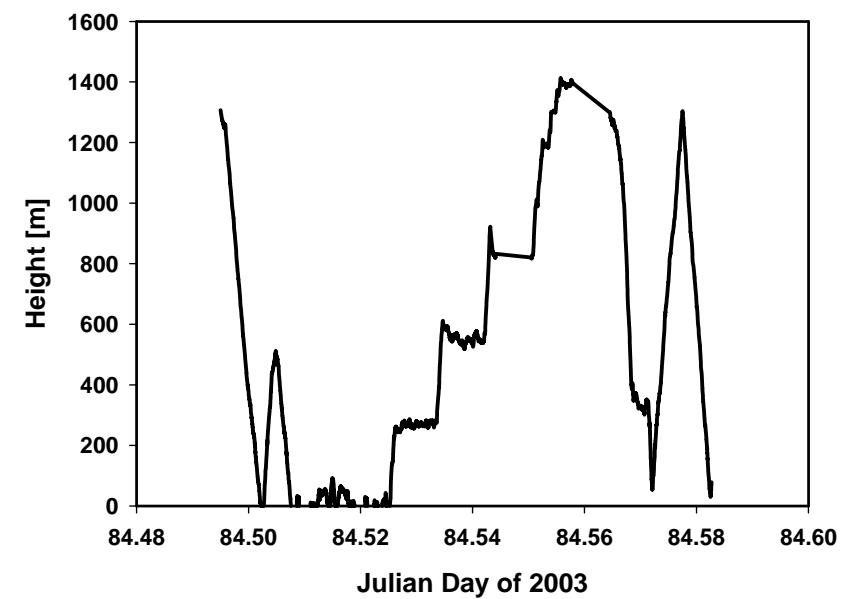

Fig. 4. Flight levels for 25th March 2003.

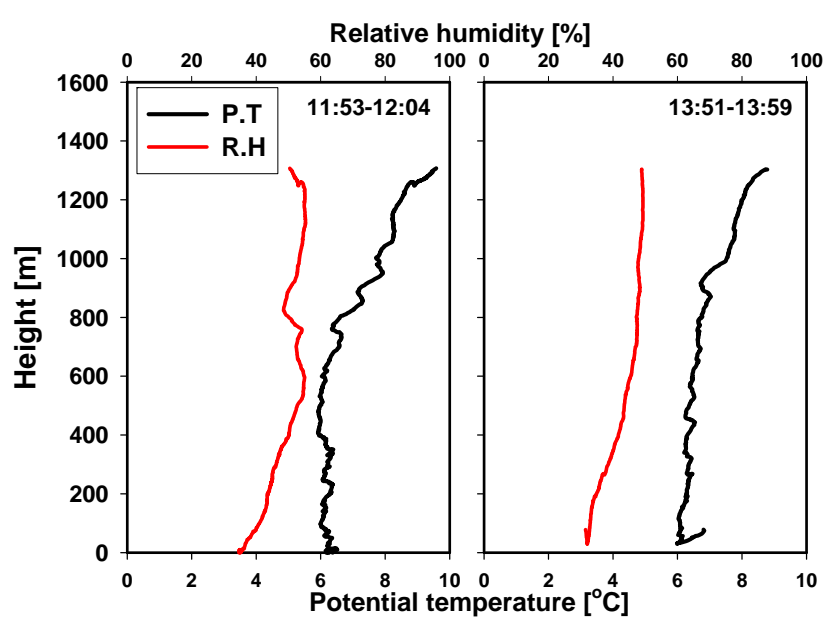

Fig. 5. Potential temperature (PT) and relative humidity (RH) boundary layer structure for 25th March 2003.

\subsection{Case study 1 - 25th March 2003}

The typical flight plan after take-off from Tampere was to transit into the defined starting area, conduct a number of ascents/descents to determine boundary layer structure and the subsequent 10-min horizontal runs, corresponding to spatial scales of $33 \mathrm{~km}$, were conducted at flights levels determined by the boundary layer structure. Figure 4 illustrates the number of ascents (2), descents (4) and horizontal runs (5) conducted during this flight. Take-off time was 11:30 and landing time was 15:00 local time.

Figure 5 displays the vertical meteorological profiles (relative humidity: R.H. and potential temperature: P.T.) for the descent (left plate) into the operations area and an ascent (right plate) out of the operations area. During the descent, there was a three-layer structure observed from the profiles: an evolving "surface" mixed layer extending up to $\sim 800 \mathrm{~m}$, a residual layer residing between 800 and $1300 \mathrm{~m}$ and the

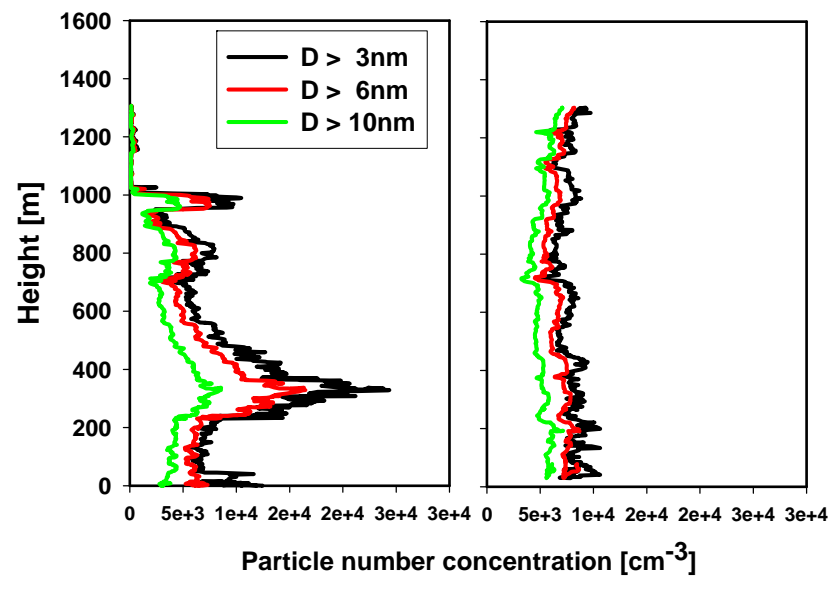

Fig. 6. Aerosol boundary layer structure for 25th Macrch 2003 Total number concentration for sizes $D>3 \mathrm{~nm}, 6 \mathrm{~nm}$ and $10 \mathrm{~nm}$. (Left) Aerosol concentration during descent from 11:53 to 12:04 local time and (Right) ascent at 13:51 to 13:49 local time. The latter profile indicates a more mixed aerosol field at the three sizes and indication that the free troposphere inversion has risen to $>1400 \mathrm{~m}$.

free troposphere above $1300 \mathrm{~m}$. During the ascent later in the flight, the mixed layer height had increased to $1000-1300 \mathrm{~m}$. The layer structure is not so defined for this case and later cases presented, nevertheless, different layers or stratification is identified by a combination of both potential temperature and relative humidity inversions - that is notable increases in potential temperature and notable reductions in relative humidity, both promoting stratification.

Figure 6 shows the aerosol profiles for the same descent and ascent. During the descent, no nucleation mode particles were detected in the Free Troposphere, however, once the aircraft entered the main boundary layer, nucleation mode particles were detected as seen by both the increase in total particle concentration and significant particle concentration differences being observed between the three CPCs measuring at sizes larger than 3, 6 and $10 \mathrm{~nm}$. Peak particle concentrations of $2 \times 10^{4} \mathrm{~cm}^{-3}$ were detected at $250-350 \mathrm{~m}$ and the concentration throughout the boundary layer was quite variable. During the ascent out of the area, some $2 \mathrm{~h}$ later, particle concentrations were more well-mixed with the total particle concentration had reduced to the order of 8000 $10000 \mathrm{~cm}^{-3}$. The figure shows that the peak enhancement of new particles occur within the mixed layer and residual layer but not in the free troposphere.

After the initial profiles to characterise the boundary layer structure, four 10-min horizontal runs were undertaken at $30 \mathrm{~m}, 300 \mathrm{~m}, 600 \mathrm{~m}$ and $900 \mathrm{~m}$ (Fig. 7). Also shown is a 10 -min run at $1500 \mathrm{~m}$ (just above the main inversion). As mentioned previously, the highest concentrations of up to $2 \times 10^{4} \mathrm{~cm}^{-3}$ were encountered in the lowest levels. One striking result of the horizontal runs is that there is a large degree of variability, suggesting that while the new particle 


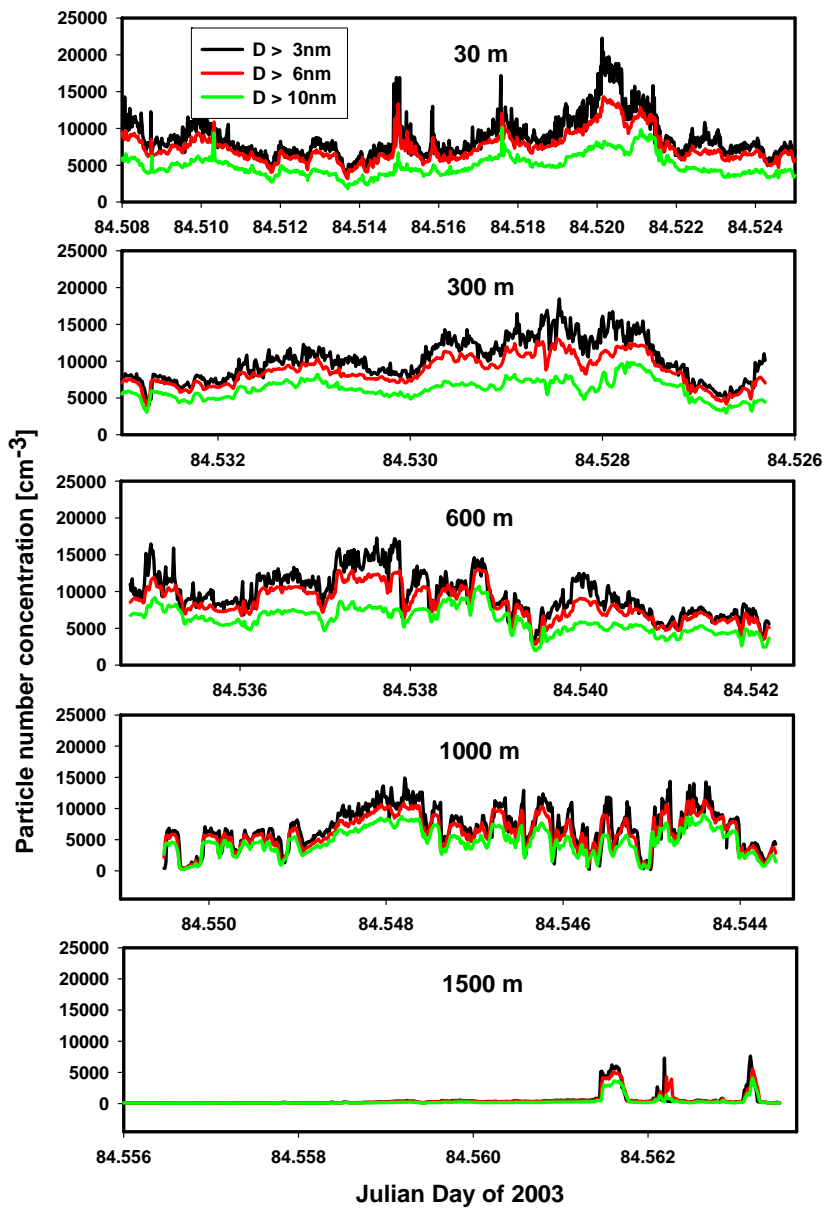

Fig. 7. Particle concentrations for $10 \mathrm{~min}$ horizontal runs at selected altitudes on 25th March 2003.

production phenomenon is clearly occurring over a large spatial scale, the event is not very homogeneous. The inhomogeneity is likely to result from the observed inhomogeneities in the local topography (forests and lakes, see Fig. 8) which can influence the surface heat fluxes driving boundary layer evolution and canopy fluxes of aerosol precursors. A similar degree of variability is seen in the meteorological parameters. Such variability can account for the lack of clear structure seen in the ascents and descents given the horizontal distance transverse during profiles.

\subsection{Case study 2-26th March 2003}

The second flight conducted was a short flight on the 26th March. The vertical profiles of aerosol concentration and meteorological parameters during the descent into the operating area are shown in Fig. 9. During this flight, the Free Troposphere inversion was located about $1100 \mathrm{~m}-1200 \mathrm{~m}$ and the main boundary layer had a three layer structure. The surface mixed layer, below $600 \mathrm{~m}$, exhibited large concentrations of nucleation mode particles while no nucleation mode parti-

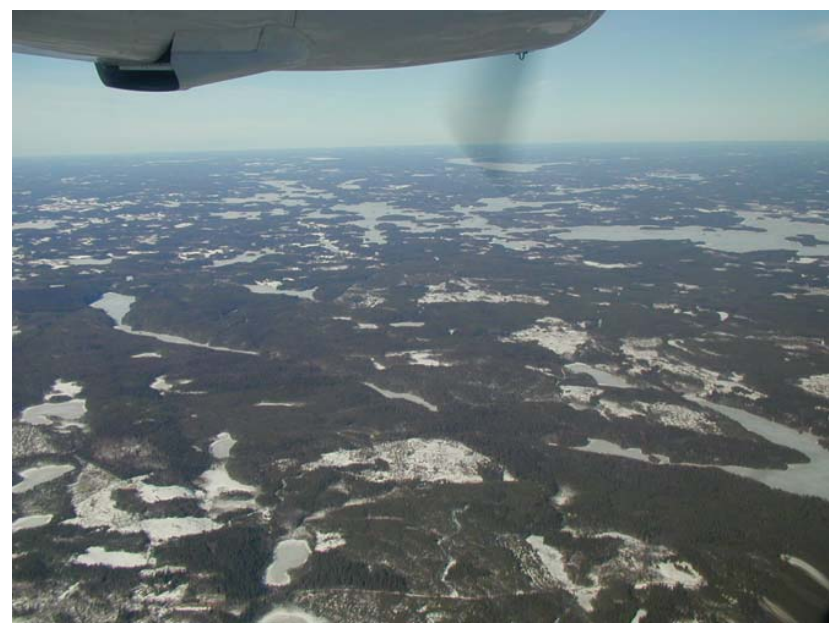

Fig. 8. Photograph of inhomogeneous land surface (forests and frozen lakes) in the operating flight area.

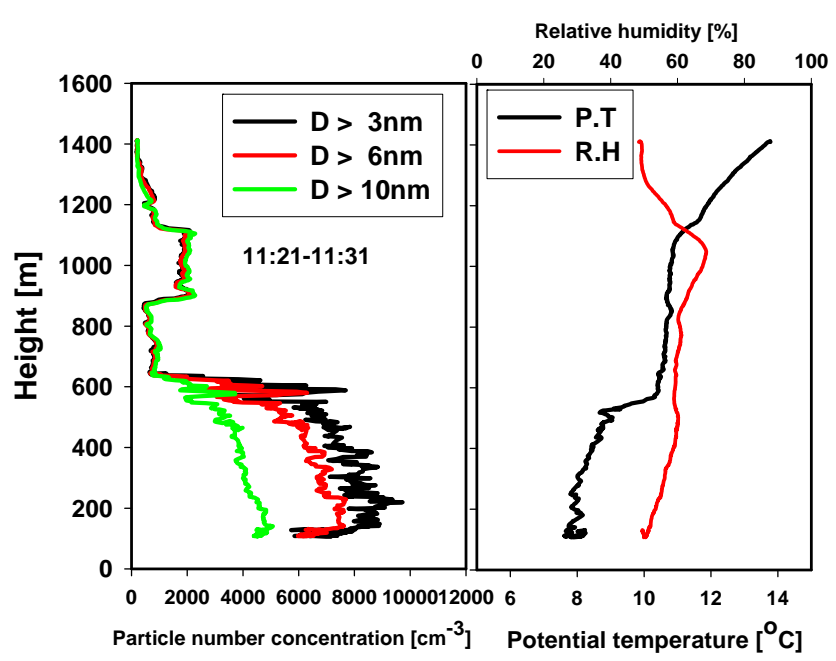

Fig. 9. Aerosol concentration potential temperature and relative humidity boundary layer structure on 26th March 2003.

cles were seen in the layer from $650-850 \mathrm{~m}$ layer or from $850-1100 \mathrm{~m}$. Two horizontal runs were conduced during this flight, one at about $120 \mathrm{~m}$ and the other around $400 \mathrm{~m}$. Particle concentrations for both runs are displayed in Fig. 10. During both reciprocal runs, at the start and end of the runs, no nucleation mode is observed; however, in the central area of each run is clearly a nucleation region with peak concentrations at sizes larger than $3 \mathrm{~nm}$ of $30000 \mathrm{~cm}^{-3}$ at $120 \mathrm{~m}$ and concentrations approaching $25000 \mathrm{~cm}^{-3}$ at $400 \mathrm{~m}$. Approximately half the nucleation mode particles resided at sizes between 3 and $6 \mathrm{~nm}$ and the other half between $6 \mathrm{~nm}$ and $10 \mathrm{~nm}$, however, it should be reiterated that no losses are accounted for and the difference between 3 and $6 \mathrm{~nm}$ and 6 and $10 \mathrm{~nm}$ particle concentration is likely to be much larger than presented. 


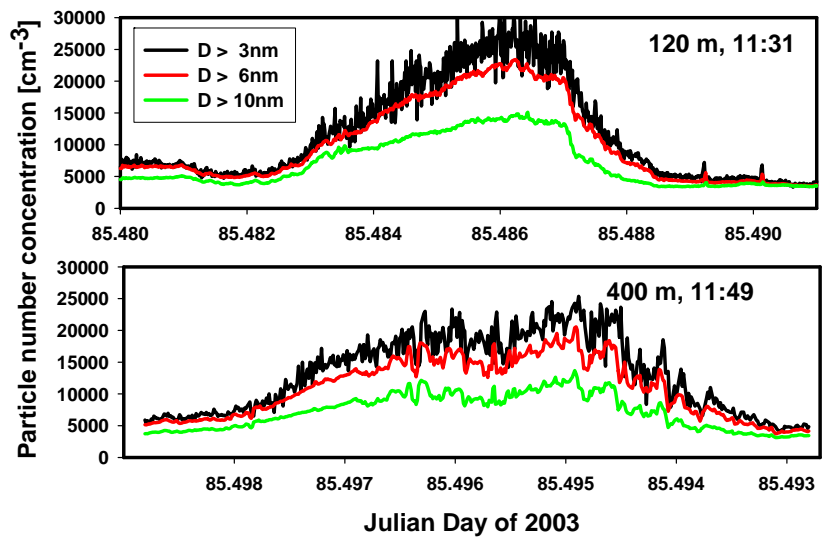

Fig. 10. Particle concentrations and horizontal variability for two selected flight levels on 26th March 2003.

\subsection{Case study 3-28th March 2003}

The third case study that we focus on was the nucleation event on 28th March 2003. Since one of the triggers of the nucleation events is thought to be the breakdown of the nocturnal boundary layer (Nilsson et al., 2001), where precursors can be concentrated, and the subsequent dilution of the aerosol condensation sink as the surface layer mixes up into the complete boundary layer, this flight mission aimed to catch the onset of nucleation as the boundary layer was breaking up. In fact, three flights were conducted using the Twin Otter and the Microlight. The Twin Otter's first flight started at 10:00 and continued until 13:00 when it landed for refuelling at Tampere airport. The second Twin Otter flight was conduced from 15:00-17:00 and the period in between was covered by the micro-light. As a result, we were able to achieve a total of $8 \mathrm{~h}$ sampling boundary layer evolution and associated nucleation events.

The Twin Otter flight levels, ascents and descents are shown in Fig. 11. The initial part of the flight conducted of series of surface layer horizontal runs $(30 \mathrm{~m})$ followed by an ascent to $1000 \mathrm{~m}$ and then a descent. The horizontal runs were started at the same fixed ground position and the ascent and descent were conducted while the aircraft was returning to this fixed ground position to start the next horizontal run.

Figure 12a shows the initial meteorological vertical structure with a well-mixed surface layer extending to $600 \mathrm{~m}$. It appears that the Free Troposphere inversion was also located at about $1400 \mathrm{~m}$ although as the flight level did not exceed $1400 \mathrm{~m}$, the full extent of the inversion is unclear. In between the evolving surface mixed layer and the Free Troposphere inversion is the residual layer. The evolution of the surface mixed layer throughout different times of the day is also shown in the same figure. The main feature is the development of the surface mixed layer up to $800-900 \mathrm{~m}$ by 10:00. Particle concentration during these ascents is also shown in Fig. $12 b$.

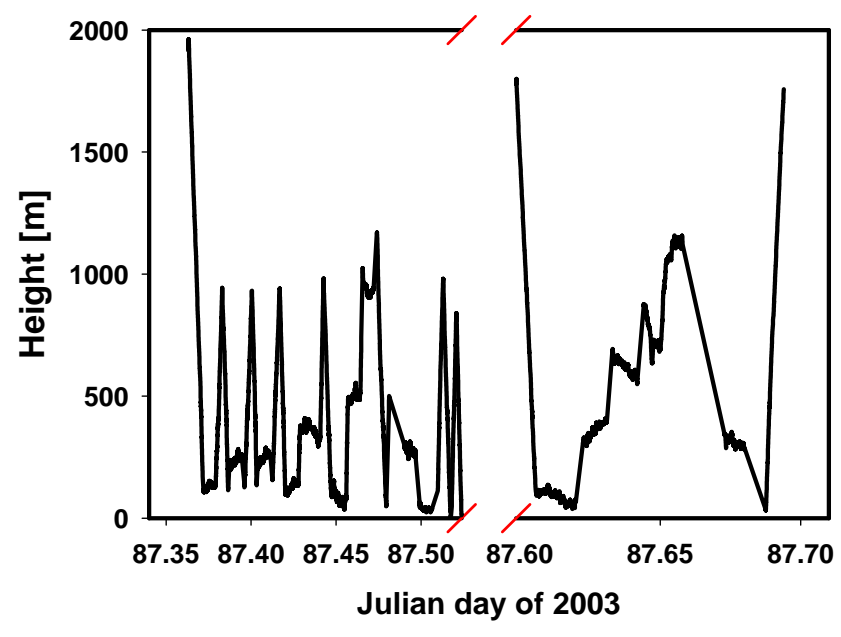

Fig. 11. Flight levels for 28th March 2003.

During the initial descent, the nucleation mode is most evident at the lowest level (just a few $m$ above the canopy top). As the boundary layer develops, the nucleation mode becomes evident throughout the boundary layer and the intensity increases. Peak concentrations of $30000 \mathrm{~cm}^{-3}$ were observed during the profile at $\sim 11: 15$. It should be noted that one should be careful in interpreting the profiles since these profiles cover significant horizontal distances over which variability is seen in both boundary layer structure, and consequently particle concentration.

Particle concentrations during the horizontal runs are shown in Fig. 13 for flight levels of 30, 150, and $300 \mathrm{~m}$ at different times throughout the morning. The first series of horizontal runs generally indicate the absence of nucleation mode particles; however, there are brief regions where nucleation is observed in small air parcels. These horizontal runs capture the onset of the nucleation event and illustrate that the nucleation event was just bubbling under as the surface layer expands vertically. As the boundary layer develops, the total particle concentration increases from background of $2500 \mathrm{~cm}^{-3}$, to $6000 \mathrm{~cm}^{-3}$ as small scale air parcels start to nucleation, to $25000 \mathrm{~cm}^{-3}$ as the nucleation event becomes fully developed.

During the latter part of the flight, the flight plan was adapted to evaluate the spatial scale of the nucleation event and, in particular, to evaluate whether or not nucleation mode particles could be observed over the frozen Gulf of Botnia or whether they were contained to areas over the forest canopy. The run out to the sea showed a decrease in nucleation mode particles as one approached the coastline and during the run at $30 \mathrm{~m}$ over the sea (which was ice-covered), no nucleation mode particles were observed (Fig. 13), as indicated by the lack of difference in concentration for the 3 CPCs. Thus, these results confirm that the nucleation event is indeed linked to processes occurring over the forest canopy and does not occur over the frozen sea. 
(a)
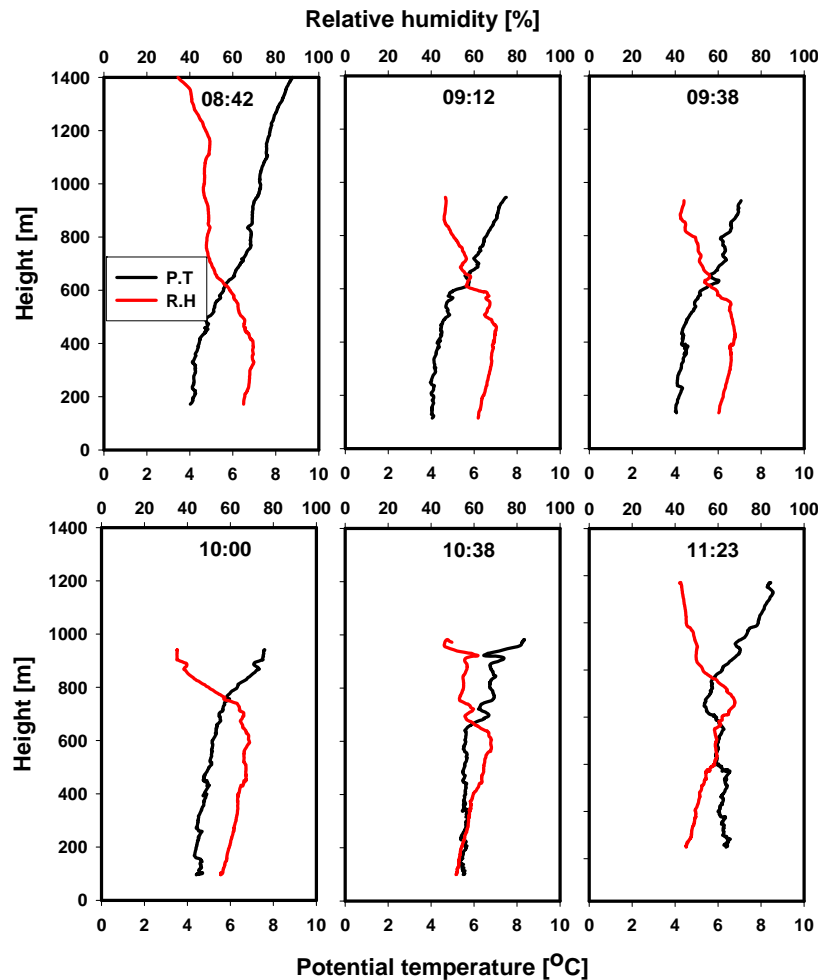

(b)
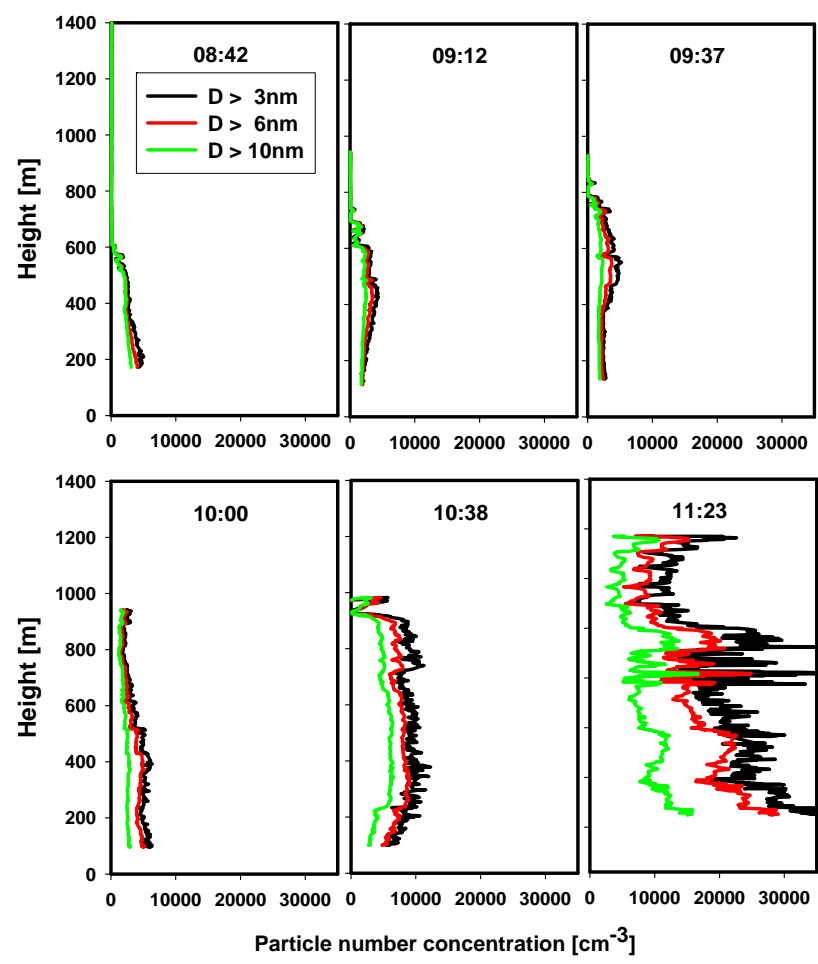

Fig. 12. (a) evolution of boundary layer structure, as determined by potential temperature and relative humidity, for 28th March 2003. (b) variation in aerosol vertical structure throughout the morning of 28th March 2003. Local time is also listed in each plot.

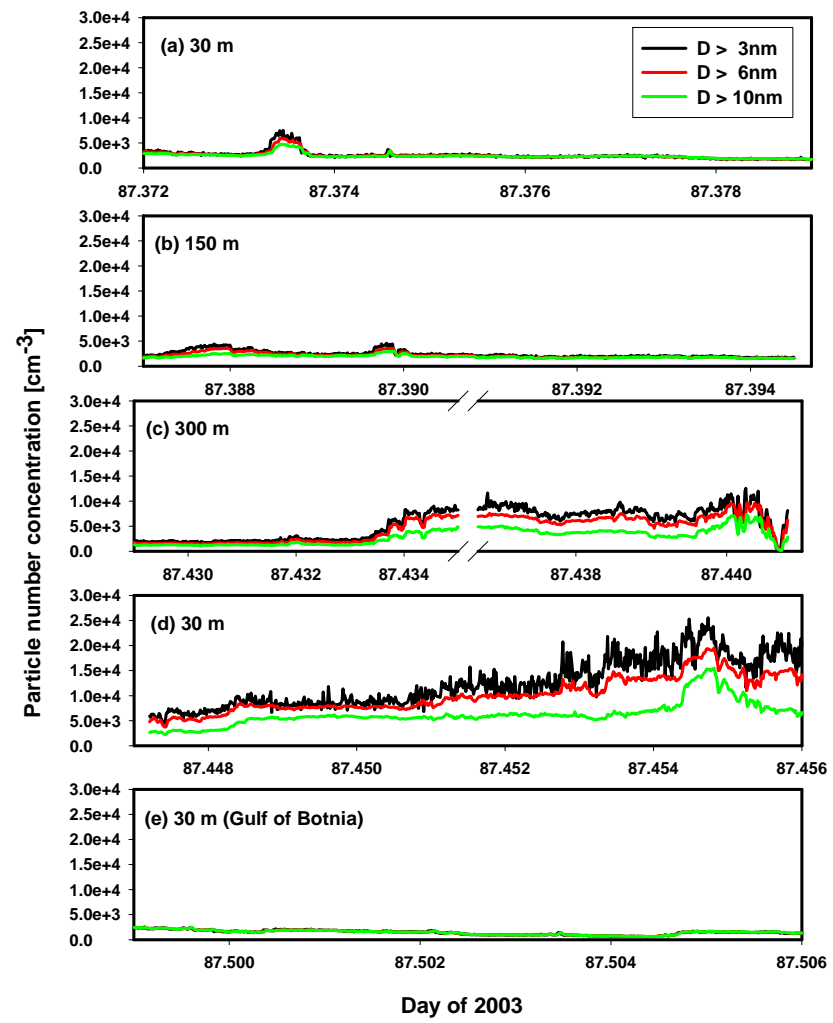

Fig. 13. Particle concentration at sizes $D>3,6$, and $10 \mathrm{~nm}$ for horizontal runs at 30, 150 and $300 \mathrm{~m}$ over the forest canopy. Also shown is the particle concentration for a $30 \mathrm{~m}$ horizontal run over the sea.

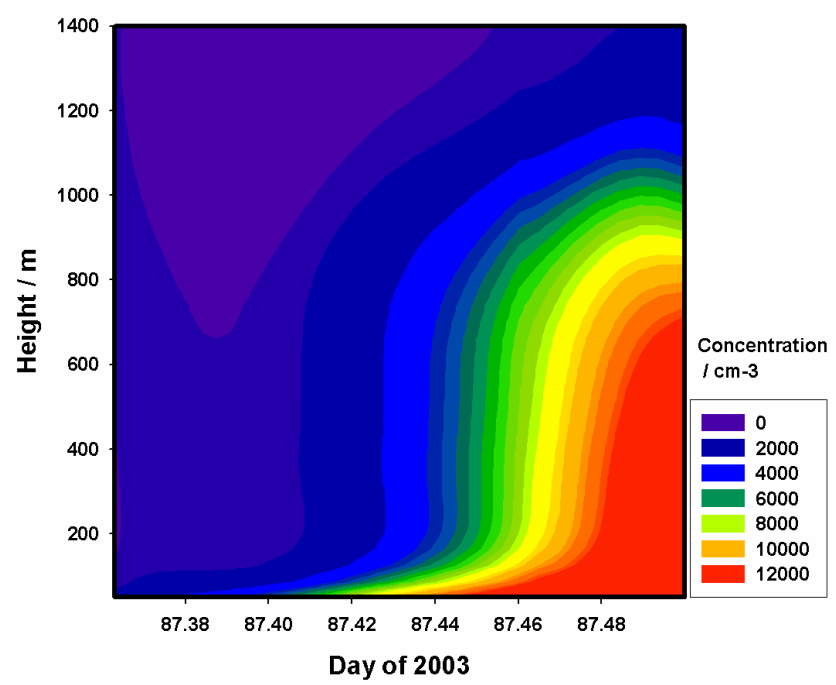

Fig. 14. Interpolated particle concentration at $\mathrm{D}>3 \mathrm{~nm}$ for 24 profiles conducted on 28th March 2003.

From the above three flights, there is strong evidence that nucleation occurs first in the surface mixed layer. In fact, we can only say that new, $3 \mathrm{~nm}$ particles are first detected in the surface mixed layer and seem to be associated with 
the break-up of the nocturnal boundary layer. We have compiled all vertical profile data of aerosol concentrations from the 24 profiles conducted throughout the day on 28th March. These are interpolated to visualise the evolution and aerosol concentration and are shown in Fig. 14. The pattern which emerges is that the first occurrence of elevated particle concentration occurs at the very lowest levels, immediately above the forest canopy and that only later in the day, as the surface mixed layer increases in height, do elevated particle concentrations appear at higher altitudes. The interpolated combination of 24 profiles strongly points to the source of new particles being just above the forest canopy.

\section{Conclusions}

Airborne measurements of nucleation mode aerosol particles were conducted over the Boreal forest during the spring (March) of 2003 and during a period of strong nucleation and growth events. Three events are presented with particle concentration increasing from $\sim 3000 \mathrm{~cm}^{-3}$ to $>20000 \mathrm{~cm}^{-3}$. The three flights indicate that no particle production is observed in the Free Troposphere and that new particles are first detected in the surface layer about $30 \mathrm{~m}$ above the canopy. The vertical and horizontal distribution of new particles demonstrated considerable variability and is thought to be due to variability in land coverage between forests and lakes. Despite the variability over horizontal scales, the production and occurrence of new particles was confined to above the forest canopy as no new particle occurrence was observed upwind of the forest over the (frozen) sea. The analyses and data presented lends strong support to the conclusion that new particles are formed close to the forest canopy, in the surface mixed layer, and not in the Free Troposphere, pointing to the forest as being the source of new particles.

Acknowledgements. This work was supported by the European Commission under Contract EVK2-CT2001-00127 (QUEST) and by Irish Research Council Science and Engineering Technology.

Edited by: V.-M. Kerminen

\section{References}

Charlson, R. J., Lovelock, J. E., Andreae, M. O., and Warren, S. G.: Oceanic Phytoplankton, Atmospheric Sulfur, Cloud Albedo And Climate, Nature, 326, 655-661, 1987.

Hansson, H. C, and O'Dowd, C. D. (eds.): Common Issues: Air Quality \& Climate - Research \& Policy, ACCENT Publication 06.4, 2006 ISBN:0-9553862-0-9, 2006.
Intergovernmental Panel on Climate Change (IPCC), Climate Change 2007: The physical scientific basis, edited by: Solomon, S., Quin, D. Manning, U. et al., Common Issues Cambridge Univ. Press, New York, USA, 2007.

Junkermann, W.: The actinic UV-radiation budget during the ESCOMPTE campaign 2001: Results of airborne measurements with the microlight research aircraft D-MIFU, Atmos. Res., 74, 461-475, 2005.

Kulmala, M., Hämeri, K., Aalto, P. P., Makela, L. M., Pirjola, L., Nilsson, E. D., Buzorius, G., Rannik, U., Dal Maso, M., Seidl, W., Hoffmann, T., Janson, R., Hansson, H.-C., Viisanen, Y., Laaksonen, A., and O'Dowd, C. D.: Overview of the international project on biogenic aerosol formation in the boreal forest (BIOFOR), Tellus B, 324-343, 2001.

Kulmala, M., Laakso, L., Lehtinen, K. E. J., Riipinen, I., Dal Maso, M., Anttila, T., Kerminen, V.-M., Horrak, U., Vana, M., and Tammet, H.: Initial steps of aerosol growth, Atmos. Chem. Phys., 4, 2553-2560, 2004,

http://www.atmos-chem-phys.net/4/2553/2004/.

Laaksonen, A., Kulmala, M., O’Dowd, C. D., Viisanen, Y., Nilsson, D., Facchini, M. C., Hoffmann, T., Arnold, F., Schell, B., and Junkermann, W.: Preliminary results from the Quest project (quantification of aerosol nucleation in the European boundary layer). In: Abstracts of the European Aerosol Conference 2003, Madrid, Spain, 31 August-5 September 2003, S1337-S1338, 2, 2003.

Nilsson, E. D., Rannik, U., Buzorius, G., and O’Dowd, C. D.: Effects of continental boundary layer evolution, convection, turbulence and entrainment on aerosol formation, Tellus B, 53, 441461, 2001.

O’Dowd, C. D., Aalto, P., Hämeri, K., Kulmala, M., and Hoffmann, T.: Atmospheric particles from organic Vapours, Nature, 416, 497-498, 2002.

O’Dowd, C. D., Facchini, M. C., Cavalli, F., Ceburnis, D., Mircea, M., Decesari, S., Fuzzi, S., Yoon, Y. J., and Putaud, J. P.: Biogenically-driven organic contribution to marine aerosol, Nature, 431, 676-680, doi:10.1038/nature02959, 2004.

O’Dowd, C. D, Yoon, Y. J., Junkermann, W., Aalto, P. P., and Lihavainen, H.: Airborne Measurements of Nucleation Mode Particles I: Coastal Atlantic Nucleation Events, Atmos. Chem. Phys., 7, 1491-1501, 2007, http://www.atmos-chem-phys.net/7/1491/2007/.

Raes, F.: Entrainment of free tropospheric aerosols as a regulating mechanism for cloud condensation nuclei in the remote marine boundary layer, J. Geophys. Res., 100, 2893-2903, 1995.

Stratmann, F., Siebert, H., Spindler, G., Wehner, B., Althausen, D., Heintzenberg, J., Hellmuth, O., Rinke, R., Schmieder U., Seidel, C., Tuch, T., Uhrner, U., Wiedensohler, A. Wandinger, U., Wendisch, M., Schell, D., and Stohl, A.: New-particle formation events in a continental boundary layer: First results from the SATURN experiment, 3, 1445-1459, Atmos. Chem. Phys., 2003.

Tunved, P., Hansson, H.-C., Kerminen, V.-M., Ström, J., Dal Maso, M., Lihavainen, H., Viisanen, Y., Aalto, P. P., Komppula, M., and Kulmala, M.: High natural aerosol loading over boreal forests, Science, 14(312), 261-263, doi:10.1126/science.1123052, 2006. 